\title{
Fator de crescimento fibroblástico básico e seus receptores em relação à atividade proliferativa na placenta bubalina em diferentes fases da gestação
}

\author{
[Basic fibloblast growth factor and its receptors in relation to proliferative activity in the buffalo \\ placenta during gestation] \\ L.P. Artoni ${ }^{1}$, C.E.B. Moura $^{2}$, E.M. Barbosa $\mathrm{Jr}^{1}$, D.B. Campos ${ }^{1}$, F.T.V Pereira ${ }^{3}$, P.C. Papa ${ }^{1}$ * \\ ${ }^{1}$ Faculdade de Medicina Veterinária e Zootecnia \\ Av. Prof. Dr. Orlando Marques de Paiva, 87 \\ 05508-900 - São Paulo, SP \\ ${ }^{2}$ Universidade Federal do Rio Grande do Norte - Natal, RN \\ ${ }^{3}$ Universidade Estadual Paulista - Dracena, SP
}

\begin{abstract}
RESUMO
Estudou-se a distribuição espaço-temporal do fator de crescimento fibroblástico básico (bFGF), do receptor 1 do fator de crescimento fibroblástico (FGFR1) e do receptor 2 do fator de crescimento fibroblástico (FGFR2) na placenta bubalina, correlacionando-a à proliferação celular. Para a detecção do bFGF, FGFR1, FGFR2 e antígeno Ki-67, colheram-se 12 placentas de búfalas nos terços inicial, médio e final da gestação, em abatedouros, e realizaram-se testes de imunoistoquímica. Detectou-se e avaliou-se a expressão do bFGF, do FGFR1, do FGFR2 e do antígeno Ki-67 ao longo da gestação. No compartimento fetal da placenta, observaram-se correlações positivas entre a expressão do bFGF e Ki-67, entre FGFR1 e Ki-67 e entre FGFR2 com Ki-67 (r=0,313, 0,358 e 0,384, respectivamente). No epitélio e estroma maternos observaram-se altas correlações entre FGFR1 e Ki-67 ( $r=0,739$ e r=0,511, respectivamente). Os resultados sugerem envolvimento do bFGF, FGFR1 e FGFR2 na proliferação do trofoblasto enquanto no compartimento materno da placenta bubalina apenas o FGFR1 atuaria como modulador dessa atividade.
\end{abstract}

Palavras-chave: búfala, placenta, fator de crescimento fibroblástico, gestação

\begin{abstract}
The space-temporal expression of basic fibroblast growth factor (bFGF), fibroblast growth factor receptor 1 (FGFR1) and fibroblast growth factor receptor 2 (FGFR2) in buffalo placenta and correlation to proliferative activity was studied. For the localization of bFGF, FGFR1, FGFR2 and Ki-67, 12 buffalo placentas from initial, middle and final gestational thirds were collected and immunohistochemistry tests were performed. Expression of bFGF and its receptors was detected and analyzed from the initial third until the end of gestation. In the fetal compartment, positive correlations were observed between the expression of bFGF and Ki-67, FGFR1 and Ki-67, besides FGFR2 and Ki-67 ( $r=0.313,0.358$ and 0.384 , respectively). High correlations were found between FGFR1 and Ki-67 in maternal epithelium and stroma ( $r=0.789$ and $r=0.511$, respectively). The results suggest that $b F G F, F G F R 1$ and FGFR2 may be involved in the modulation of trophoblast proliferation, whereas maternal compartment proliferation in the buffalo placenta would only be modulated by FGFR1.
\end{abstract}

Keywords: buffalo, placenta, fibroblast growth factor, pregnancy

Recebido em 1 de novembro de 2005

Aceito em 20 de abril de 2007

*Autor para correspondência (corresponding author)

E-mail: ppapa@usp.br 


\section{INTRODUÇÃO}

O fator de crescimento fibroblástico básico (bFGF) regula a angiogênese, o crescimento e o desenvolvimento placentário (Zheng et al., 1997) além de estimular a proliferação e diferenciação das células da placenta (Ferriani et al., 1994). O bFGF é um membro da família dos FGF composta por 24 isoformas até o momento identificadas (Fischer et al., 2003).

Foram identificadas cinco isoformas do bFGF humano, que se originam a partir de derivação alternativa (Prats et al., 1989). A isoforma de baixo peso molecular (18kDa) é citoplasmática e sua ação acontece de maneira autócrina e parácrina; as demais são denominadas isoformas de alto peso molecular $(22 ; 22,5 ; 24$ e $34 \mathrm{KDa})$, apresentam localização nuclear e provavelmente atuam de maneira intrácrina (Arese et al., 1999).

A localização nuclear, além de estar associada à atividade proliferativa ou ao estado de ativação celular (Yu et al., 1993), pode também estar associada à redistribuição do bFGF, localizado no citoplasma para o núcleo. No entanto, a isoforma de baixo peso molecular do bFGF dificilmente é observada em frações nucleares (Renko et al., 1990).

O bFGF liga-se a receptores de alta afinidade (receptores com atividade tirosina quinase), o que resulta na indução da autofosfoliração do receptor e da fosforilação dos substratos da tirosina, bem como dos substratos das quinases e pode estimular atividades celulares como proliferação, motilidade e diferenciação (Fantl et al., 1993). A família dos receptores de alta afinidade do FGF (FGFR) é composta até o momento por cinco genes identificados e uma grande variedade de subtipos formados a partir de derivação alternativa. O bFGF ativa preferencialmente as isoformas que apresentam derivação c do domínio extracelular III (Powers et al., 2000; Pfarrer et al., 2003).

Assim como o bFGF, os FGFR também são translocados para o núcleo, como demonstrado em gliomas e astrócitos humanos (Joy et al., 1997). Esse transporte acontece por meio de uma proteína solúvel que trafega entre o citoplasma e o núcleo, a importina- $\beta$. Essa atua diretamente ou em conjunto com proteínas de adaptação, que, por sua vez, interagem com outras proteínas com sinal de localização nuclear (NLS). O FGFR1 é translocado ao núcleo juntamente com o bFGF, o qual apresenta NLS (Stachowiak et al., 2003). Uma vez no núcleo, este receptor estimula a transcrição de diversos genes, entre eles o da tirosina hidroxilase, estimulação denominada de sinalização integrativa do FGFR1 nuclear (Myers et al., 2003). Também foi relatada a localização do FGFR2 no núcleo de células do dente humano, mas seu mecanismo de ação não foi descrito (So et al., 2001).

O ciclo celular compreende os processos que ocorrem desde a formação de uma célula até a sua própria divisão em duas células filhas. Os anticorpos para Ki-67 localizam o antígeno nuclear expresso em todas as fases do ciclo celular, exceto as fases de G0 e o início da fase de G1 (Gerdes et al., 1984).

Durante a gestação, o útero passa por intensas alterações morfológicas a fim de acomodar o crescimento do concepto, e a placenta sofre intenso e rigoroso processo de proliferação celular ao longo da gestação. Sua regulação exige balanço entre fatores promotores ou inibidores do ciclo celular (Bamberger et al., 1999; Correia-da-Silva et al., 2004; Pfarrer et al., 2006). Nesse período, qualquer comprometimento na formação e no desenvolvimento placentário prejudica 0 desenvolvimento fetal e o sucesso da gestação (Redmer et al., 2004).

Este trabalho teve o objetivo de quantificar a expressão espaço-temporal da proteína do bFGF, FGFR1 e FGFR2 e correlacioná-la à expressão do Ki-67 ao longo da gestação.

\section{MATERIAL E MÉTODO}

Em abatedouros dos estados de São Paulo e Paraná, foram coletados 12 úteros gravídicos de búfalas. A mensuração dos fetos foi realizada para avaliação do estádio da gestação. As placentas foram distribuídas em três grupos segundo o estádio da gestação: 100 dias $(n=4)$; 150 dias $(n=4) ; 300$ dias $(n=4)$. De cada placenta, três placentomas foram coletados aleatoriamente e perfundidos com solução tampão fosfato (PBS), pH 7,2 e, em seguida, com formol tamponado a $4 \%$. Fragmentos de $3 \mathrm{~mm}^{3}$, fixados 
na mesma solução por 24 horas, foram lavados em PBS. A inclusão do material se deu em Histosec ${ }^{\circledR 1}$.

Cortes de $5 \mu \mathrm{m}$ foram colocados sobre lâminas tratadas com aminopropiltrietoxisilano. Para realização da imunoistoquímica, utilizaram-se tampão citrato para exposição dos epítopos, peróxido de hidrogênio em metanol a $1 \%$ para inativação da peroxidase endógena e soro eqüino para bloqueio de reações cruzadas. A incubação com os anticorpos primários foi feita por 20 horas a $4^{\circ} \mathrm{C}$ e com o anticorpo secundário, por 20 minutos em temperatura ambiente ( $\mathrm{Tab} 1$ ). O complexo avidina-biotina-peroxidase $^{2}$ foi utilizado para potencializar e o Nova $\operatorname{Red}^{\circledR 3}$, para revelar a reação. Para os controles negativos da reação, a incubação com o anticorpo primário foi substituída por incubação com PBS.

Tabela 1. Anticorpos primários e secundários utilizados para testes imunoistoquímicos na placenta de búfalas em diferentes estádios da gestação

\begin{tabular}{lcccc}
\hline Anticorpo primário & Clone (isotipo) & Hospedeiro & Diluição & Fornecedor $\left(\right.$ cat $\left.\mathrm{n}^{\circ}\right)$ \\
\hline bFGF & BFM-2 & Bovino & $1: 100$ & Upstate 05-118 \\
FGFR1 & 19B2 & Camundongo & $1: 100$ & Upstate 05-149 \\
FGFR2 & Policlonal & Coelho & $1: 200$ & Sigma F 0300 \\
Ki-67 & MB67 & Camundongo & $1: 10$ & Biosource AHF0342 \\
Anticorpo secundário & Clone (isotipo) & Hospedeiro & Diluição & Fornecedor (cat $\left.n^{\circ}\right)$ \\
$\begin{array}{l}\text { Anticamundongo/anticoelho } \\
\text { biotinilado) }\end{array}$ & IgG (H+L) & Cavalo & \multirow{2}{*}{$1: 200$} & \multirow{2}{*}{ Vector (BA-1400) } \\
\hline
\end{tabular}

bFGF: fator de crescimento fibroblástico básico; FGFR1: receptor 1 do fator de crescimento fibroblástico; FGFR2: receptor 2 do fator de crescimento fibroblástico; Ki-67: antígeno nuclear.

A avaliação da reação foi feita em microscópio óptico com aumento de 400 vezes, e as imagens foram capturadas com auxílio do sistema de imagens KS-400. Para avaliação da atividade proliferativa do bFGF por meio da ligação a dois de seus receptores na placenta bubalina ao longo da gestação, quantificou-se a expressão nuclear das proteínas do bFGF, FGFR1, FGFR2 e Ki-67 em diferentes tipos celulares para posterior realização de testes estatísticos de correlação de Pearson (r).

\section{RESULTADOS E DISCUSSÃO}

Nas placentas de 100 dias, foi detectada fraca reação (RN) nas células dos estromas fetal e materno e forte $\mathrm{RN}$ nos epitélios materno e fetal. (Fig. 1A). Placentas de 150 dias apresentaram fraca reação para o bFGF no núcleo das células dos estromas fetal e materno e no epitélio materno, e moderada nas células do epitélio fetal (Fig. 1B). As placentas de 300 dias apresentaram reação fraca no estroma fetal, moderada no estroma e epitélio maternos e forte no epitélio fetal (Fig. 1D).

Ao ser analisada a expressão do FGFR1 no núcleo das células da placenta bubalina, foi possível observar que placentas de 100 dias apresentaram reações fraca e moderada para os estromas fetal e

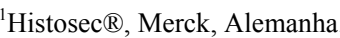

${ }^{2} \mathrm{ABC}$ Elite Kit ${ }^{\circledR}$, Vector, Alemanha.

${ }^{3}$ Nova Red ${ }^{\circledR}$, Vector, Alemanha. materno, respectivamente, reação moderada no epitélio fetal e forte no epitélio materno (Fig. 2A). Placentas de 150 dias não apresentaram reação para FGFR1 no estroma materno, mas reação fraca foi observada no estroma fetal, e moderada nos epitélios materno e fetal (Fig. 2B). Placentas de 300 dias apresentaram reação fraca nos estromas fetal e materno, ausente no epitélio fetal e moderada no epitélio materno (Fig. 2D).

Na expressão da proteína do FGFR2 no núcleo das células da placenta bubalina, foi possível observar que as placentas de 100 dias apresentaram reação negativa no estroma materno, fraca no estroma fetal e epitélio materno, e moderada no epitélio fetal (Fig. 3A). Nas placentas de 150 dias, a reação foi negativa no estroma materno e fraca nos epitélios fetal e materno e estroma fetal (Fig. 3B). Para as placentas de 300 , dias, não houve reação no estroma materno, mas houve reação fraca no estroma fetal, e moderada nos epitélios fetal e materno (Fig. 3D).

Quanto à expressão do antígeno Ki-67, placentas de 100 e 150 dias apresentaram reação fraca ou moderada nos estromas e epitélios materno e fetal (Fig. 4A e B). Em placentas de 300 dias, a expressão foi fraca nos estromas fetal e materno e epitélio fetal, e moderada no epitélio materno (Fig. 4D). 

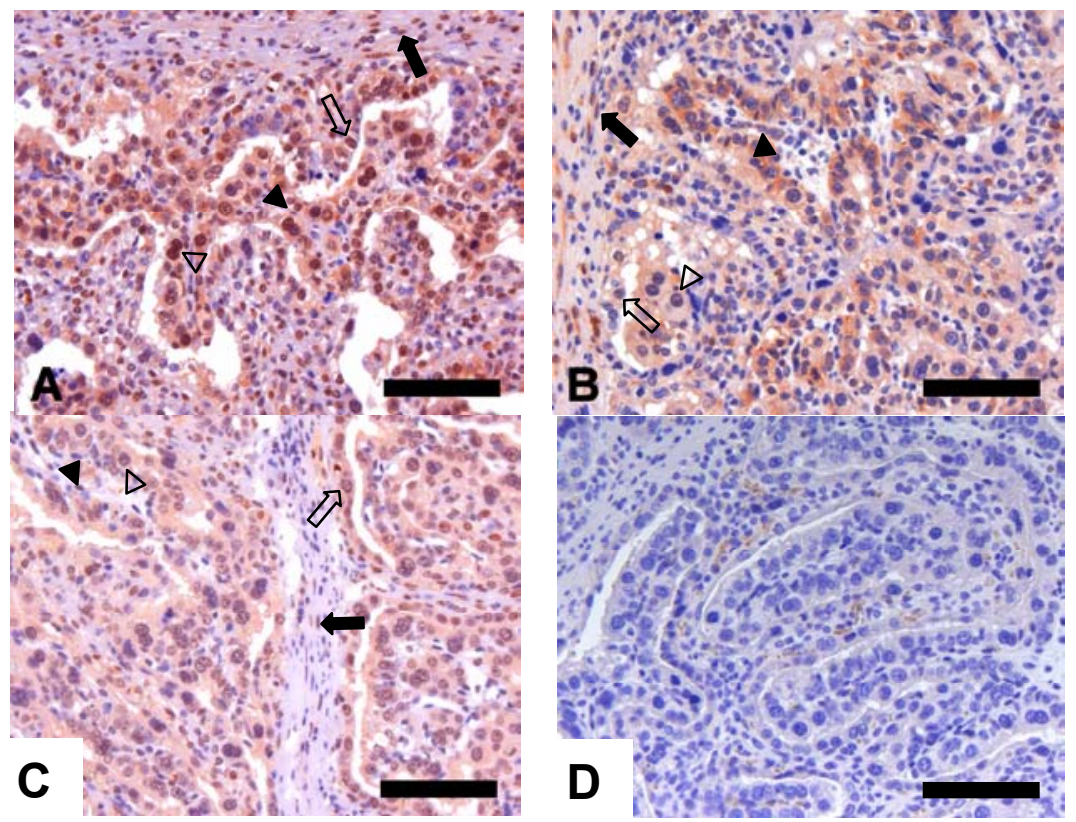

Figura 1. Fotomicrografias da localização da proteína do bFGF na placenta de búfalas quando utilizado o anticorpo primário monoclonal anti-bFGF, BFM-2. A: 100 dias; B: 150 dias; C: 300 dias; D: controle negativo. Observar a reação nuclear positiva para o fator de crescimento em células do estroma materno (seta), do epitélio materno (seta vazia), do epitélio fetal (ponta de seta vazia) e do estroma fetal (ponta de seta). Barra: $100 \mu \mathrm{m}$
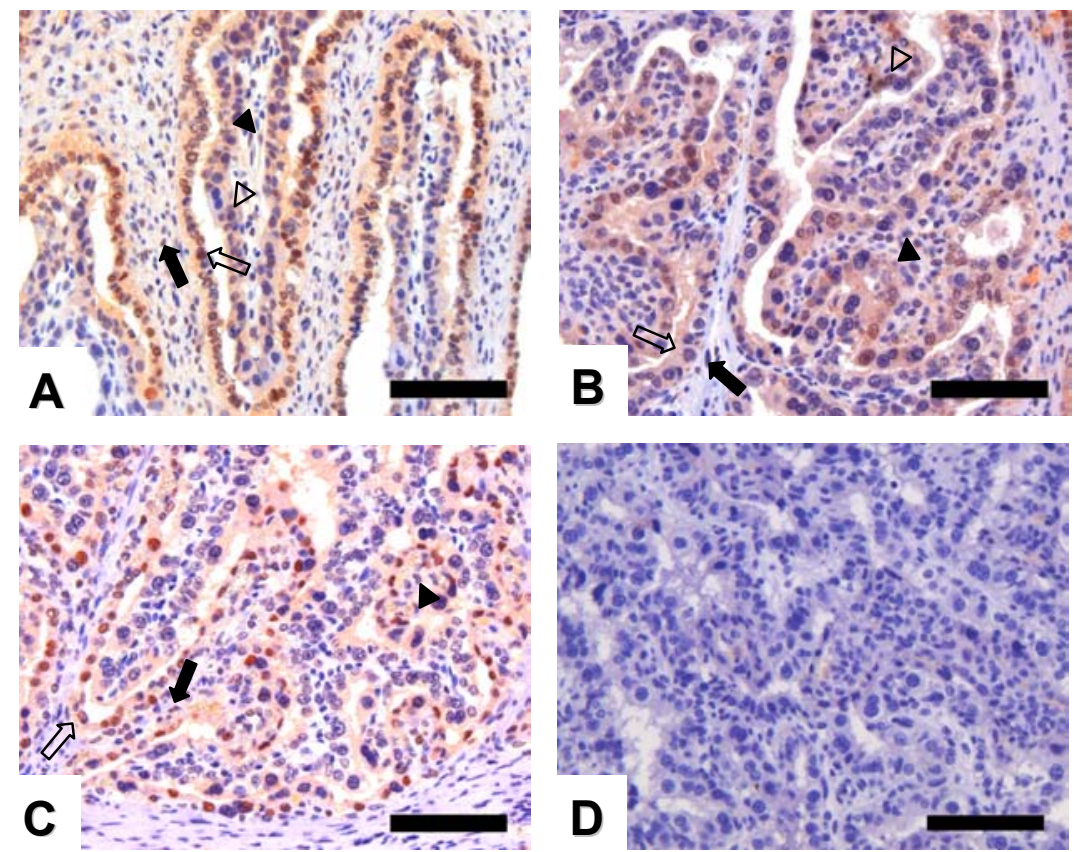

Figura 2. Fotomicrografias da localização da proteína do FGFR1 na placenta de búfalas quando utilizado o anticorpo primário monoclonal anti-FGR1, 19B2. A: 100 dias; B: 150 dias; C: 300 dias; D: controle negativo. Observar a reação nuclear positiva para o receptor do fator de crescimento em células do estroma materno (seta), do epitélio materno (seta vazia), do epitélio fetal (ponta de seta vazia) e do estroma fetal (ponta de seta). Barra: $100 \mu \mathrm{m}$ 

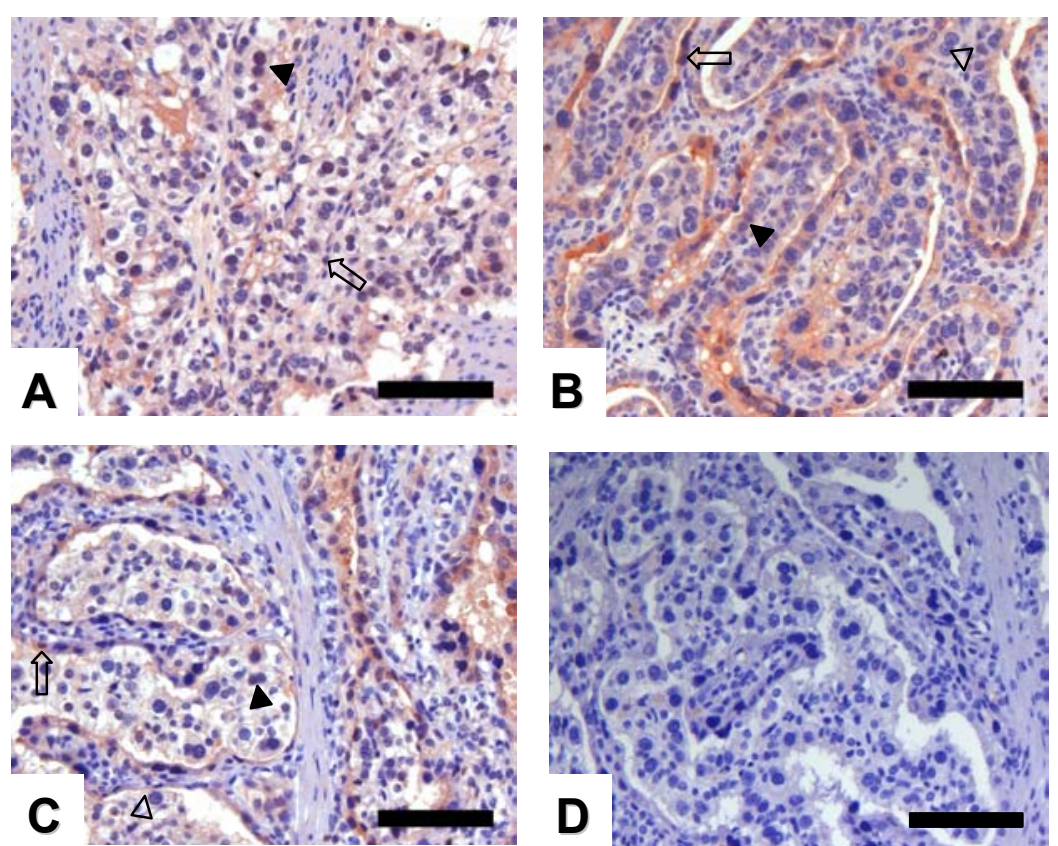

Figura 3. Fotomicrografias da localização da proteína do FGFR2 na placenta de búfalas quando utilizado o anticorpo primário policlonal anti-FGFR2. A: 100 dias; B: 150 dias; C: 300 dias; D: controle negativo. Observar a reação nuclear positiva para o receptor do fator de crescimento em células do epitélio materno (seta vazia), do epitélio fetal (ponta de seta vazia) e do estroma fetal (ponta de seta). Barra: 100 $\mu \mathrm{m}$
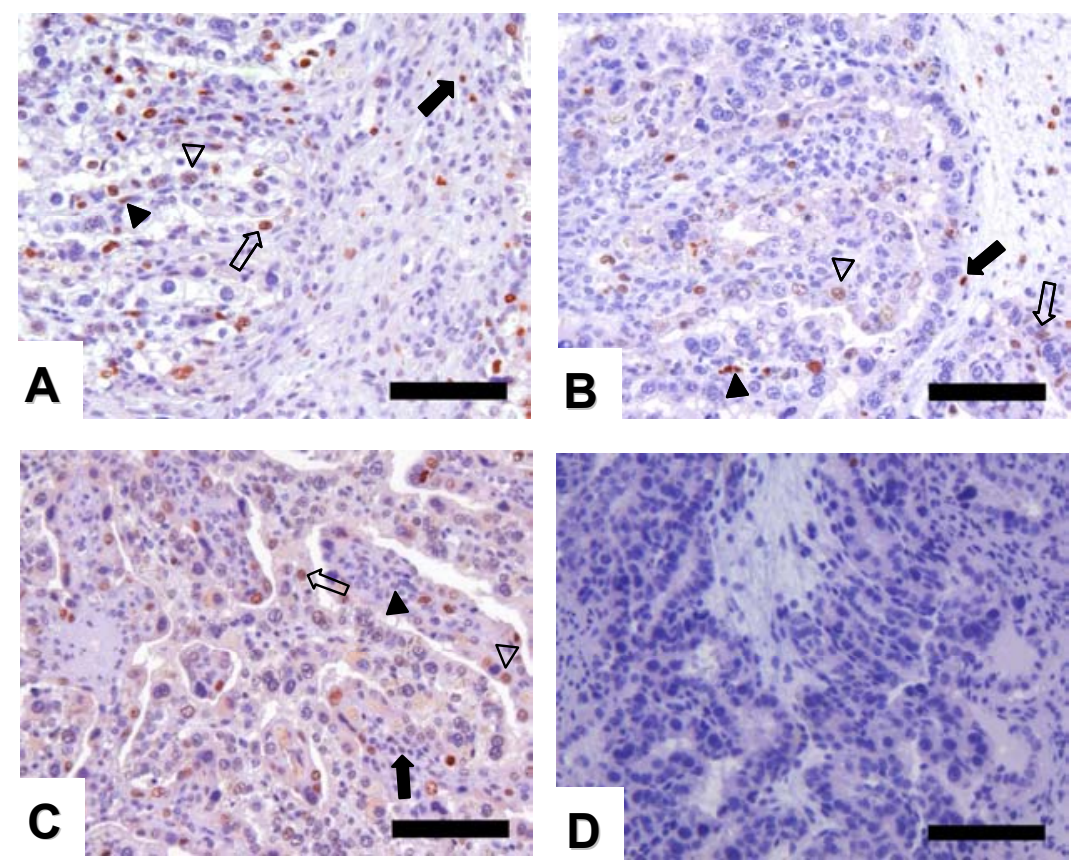

Figura 4. Fotomicrografias da localização da proteına do Ki-67 na placenta de búfalas. Reações de imunoistoquímica utilizando o anticorpo monoclonal anti-Ki-67, MB67. A: 100 dias; B: 150 dias; C: 300 dias; D: controle negativo. Observar a reação nuclear positiva para o antígeno nuclear em células do estroma materno (seta), do epitélio materno (seta vazia), do epitélio fetal (ponta de seta vazia) e do estroma fetal (ponta de seta). Barra: $100 \mu \mathrm{m}$ 
$\mathrm{Na}$ Tab 2 apresentam-se os valores encontrados para expressão do bFGF, seus receptores 1 e 2 e o marcador de proliferação celular Ki-67 na placenta bubalina em diferentes fases da gestação.

Tabela 2. Expressão do bFGF, seus receptores 1 e 2 e Ki-67 na placenta bubalina em diferentes fases da gestação

\begin{tabular}{|c|c|c|c|}
\hline$\overline{\mathrm{bFGF}}$ & 100 dias & 150 dias & 300 dias \\
\hline Estroma materno & 2 & 2 & 3 \\
\hline Epitélio materno & 4 & 2 & 3 \\
\hline Epitélio fetal & 4 & 3 & 4 \\
\hline Estroma fetal & 2 & 2 & 2 \\
\hline FGFR1 & 100 dias & 150 dias & 300 dias \\
\hline Estroma materno & 3 & 1 & 2 \\
\hline Epitélio materno & 4 & 3 & 3 \\
\hline Epitélio fetal & 3 & 3 & 1 \\
\hline Estroma fetal & 2 & 2 & 2 \\
\hline FGFR2 & 100 dias & 150 dias & 300 dias \\
\hline Estroma materno & 1 & 1 & 1 \\
\hline Epitélio materno & 2 & 2 & 3 \\
\hline Epitélio fetal & 3 & 2 & 3 \\
\hline Estroma fetal & 2 & 2 & 2 \\
\hline $\mathrm{Ki}-67$ & 100 dias & 150 dias & 300 dias \\
\hline Estroma materno & 2 & 2 & 2 \\
\hline Epitélio materno & 2 & 2 & 3 \\
\hline Epitélio fetal & 2 & 2 & 2 \\
\hline Estroma fetal & 2 & 2 & 2 \\
\hline \multicolumn{4}{|c|}{$\begin{array}{l}\text { 1: reação ausente; 2: reação fraca; } 3 \text { : reação } \\
\text { moderada; 4: reação forte. bFGF: fator de } \\
\text { crescimento fibroblástico básico; FGFR1 } \\
\text { receptor } 1 \text { do fartor de crescimento fibroblástico } \\
\text { FGFR2: receptor } 2 \text { do fator de crescimento } \\
\text { fibroblástico: Ki-67: antígeno nuclear. }\end{array}$} \\
\hline
\end{tabular}

Pela correlação de Pearson, observou-se que, nas células do epitélio fetal da placenta de búfalas, houve correlação positiva entre o bFGF e o antígeno Ki-67 ( $\mathrm{r}=0,313, \mathrm{P}=0,019)$. No epitélio e no estroma maternos, as correlações entre $\mathrm{O}$ FGFR1 e o antígeno $\mathrm{Ki}-67$, foram positivas $\mathrm{r}=0,739 \quad(\mathrm{P}<0,0001) \quad$ e $\mathrm{r}=0,511 \quad(\mathrm{P}<0,0001)$, respectivamente, e no epitélio fetal, a correlação foi positiva entre FGFR2 e Ki-67, $r=0,384$ $(\mathrm{P}=0,0035)$

$\mathrm{Na}$ literatura observou-se que este é o primeiro trabalho a relatar a presença desse fator de crescimento e seus receptores na placenta de búfalas e a ressaltar o perfil de expressão em diferentes fases da gestação.

A expressão citoplasmática e a nuclear do bFGF, FGFR1 e FGFR2 nas células da placenta bubalina a partir do primeiro terço até o final da gestação são condizentes com resultados descritos por Pfarrer et al. (2003) e Campos
(2005) na placenta de bovinos. A expressão nuclear do bFGF também pode ser observada em células da placenta humana (Cattini et al., 1991). Em estudos realizados por Davis et al. (1997) e Quarto et al. (1991), observou-se que as isoformas do bFGF localizadas no núcleo apresentaram maior eficiência no aumento da síntese de DNA que a isoforma de baixo peso molecular, a qual não foi encontrada no núcleo até o momento. Demonstrou-se também que a expressão do bFGF e seu receptor FGFR1 no núcleo está correlacionada à proliferação de astrócitos e constitutivamente presentes em núcleos de gliomas em proliferação contínua (Joy et al., 1997), e estimulam a transcrição de diversos genes (Myers et al., 2003). A localização nuclear do FGFR2 também foi relatada (So et al., 2001), o que possivelmente contribui para o aumento do processo de transcrição. Por esse motivo, optou-se apenas pela contagem da reação nuclear para realização da análise de correlação com a expressão do antígeno nuclear Ki-67.

Ao analisarem o compartimento fetal da placenta do macaco Rhesus, Wei et al. (2004) notaram diminuição da expressão da proteína e do mRNA do bFGF de acordo com o avanço da gestação, assim como observado na placenta humana (Ferriani et al., 1994). Resultados semelhantes foram observados neste estudo, uma vez que a expressão da proteína do bFGF foi menor ao final da gestação bubalina e pode também estar relacionada à diminuição geral da transcrição gênica nessa fase, segundo Blasio et al. (1997).

Em estudos realizados durante a formação do trofoblasto a partir de cultura de blastocistos de coelhos (Grundker e Kirchner, 1996), observouse a expressão da proteína do bFGF no blastocisto já em fase inicial de gestação, apontando para a importância desse fator de crescimento na formação do trofoblasto. A expressão do bFGF na placenta deve sustentar, portanto, o desenvolvimento fetal e o próprio desenvolvimento placentário. No presente estudo, o valor da correlação entre a expressão desse fator de crescimento e o antígeno Ki-67 nas células do epitélio fetal da placenta da búfala pode ser explicado pela variação da proliferação celular observada entre os diferentes estádios de gestação estudados (Fig. 5A). Observou-se maior convergência na segunda metade da gestação. 

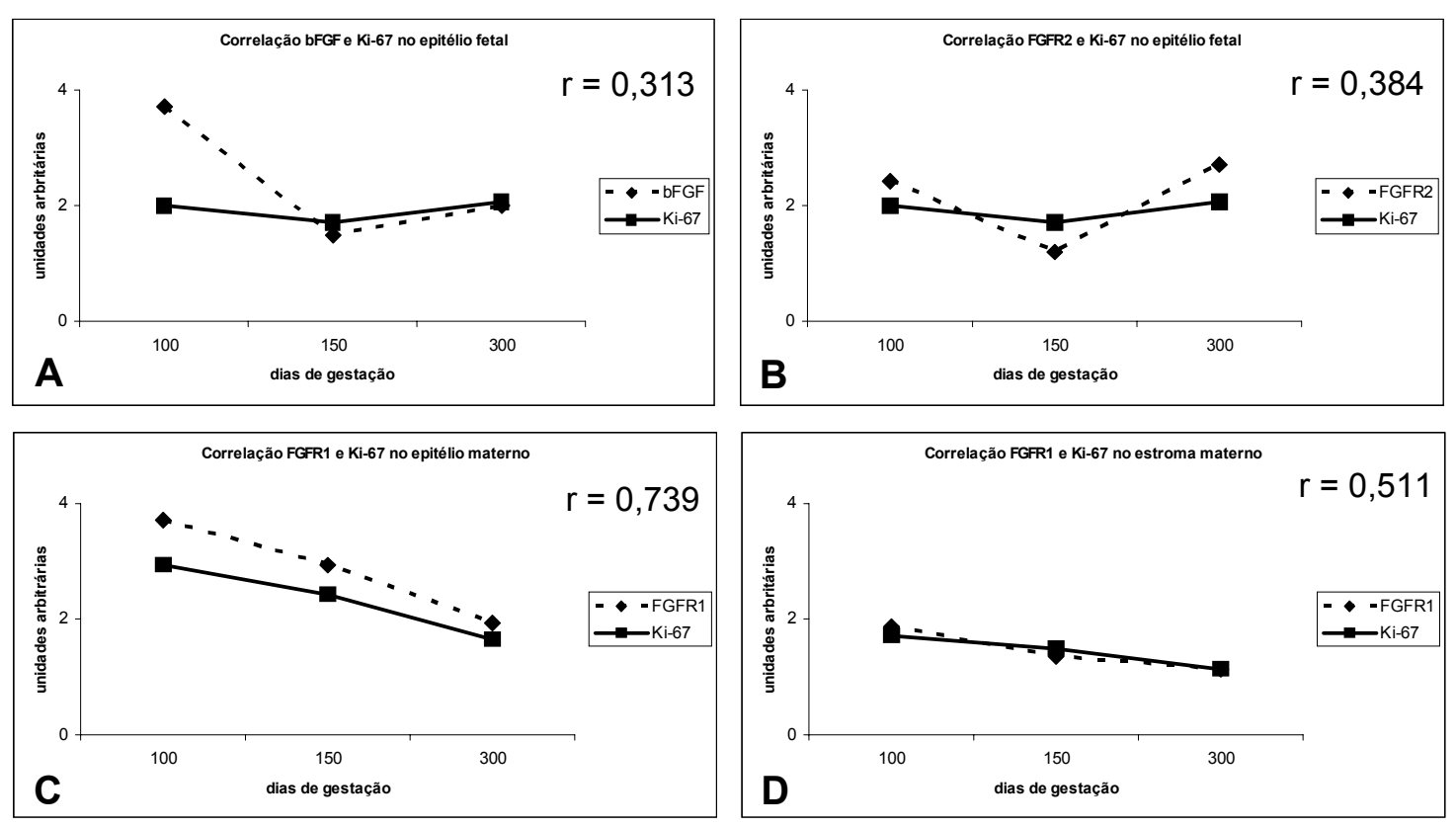

Figura 5. Perfil da correlação de Pearson (r) encontrada para o bFGF e seus receptores (linhas tracejadas) em relação ao antígeno Ki-67 (linha contínua) ao longo da gestação. Observa-se correlação positiva no epitélio fetal entre o bFGF e o Ki-67 (A) e entre o FGFR2 e o Ki-67 (B); no epitélio materno, entre o FGFR1 e o Ki-67 (C), e no estroma materno, entre o FGFR1 e o Ki-67 (D).

Wei et al. (2004) relataram maior expressão do FGFR1 no compartimento fetal da placenta do macaco Rhesus nos estádios iniciais da gestação. Também foi observado que as células endoteliais não expressaram esse receptor, sugerindo modulação de outras funções do bFGF, que não a de angiogênese, isto é, provavelmente estimulação da proliferação e diferenciação do trofoblasto por meio da sinalização de vias autócrinas e parácrinas. $\mathrm{O}$ presente estudo demonstrou uma expressão mais intensa do FGFR1 no compartimento materno da placenta no início da gestação e correlação positiva entre FGFR1 e o antígeno Ki-67, ao longo da gestação.

Segundo Pfarrer et al. (2006), a expressão do mRNA do FGFR2 na placenta de bovinos foi maior aos 80 e 200 dias de gestação, entretanto, neste estudo, a expressão do FGFR2 diminuiu ao longo da gestação, assim como observado por Baczyk et al. (2005), que avaliaram a expressão do FGFR2 nas células trofoblásticas de ratos. Segundo Orr-Urtreger et al. (1993), o FGFR2 é expresso principalmente por células epiteliais e é essencial para a fusão corioalantóica e para a modulação da atividade proliferativa do trofoblasto. Isso foi comprovado por $\mathrm{Xu}$ et al. (1998), ao cultivarem linhagens de células-tronco embrionárias nas quais inseriram um inibidor da atividade do FGFR2 e observaram bloqueio da atividade proliferativa do epitélio fetal, ocasionando má formação da porção labiríntica da placenta de ratos. Este estudo permitiu também a observação da importante correlação entre a expressão dessa proteína e o estímulo da atividade mitogênica para a proliferação e formação da parte trofoblástica da placenta.

Em bovinos, o antígeno Ki-67 foi localizado na maioria das células do epitélio materno da placenta, e sua expressão diminuiu ao término da gestação (Boos et al., 2003). Os resultados observados neste trabalho para o epitélio materno da placenta bubalina são condizentes com aqueles encontrados por Boos et al. (2003). Estudos realizados por Hoffmann e Schuler (2002), no entanto, relataram diminuição da expressão desse antígeno nessas células aos 220 dias, seguido por intenso aumento até próximo ao parto.

Segundo Boos et al. (2003), a imunorreatividade ao antígeno Ki-67 nas células do epitélio fetal e materno da placenta de bovinos indica que a proliferação celular é fundamental para a manutenção da gestação e está mais presente na 
porção materna que na fetal, o que se reflete nas observações macro e microscópicas de cada compartimento, uma vez que o compartimento materno apresenta maior capacidade de crescimento que o fetal (Laven e Peters, 2001). Os achados deste estudo, que, por meio de testes de imunoistoquímica, determinaram maior expressão desse marcador de proliferação celular nas células do epitélio materno que nas do epitelio fetal, assemelham-se aos resultados encontrados por Boos et al (2003). Essa alta expressão do antígeno Ki-67 pelas células do epitélio materno da placenta bovina indica que a proliferação elevada pode estar relacionada também à nutrição do feto (Boos et al., 2003; Hoffmann e Schuler, 2002).

Sugere-se que a ligação do bFGF ao seu receptor FGFR2 no epitélio fetal favorece a estimulação da proliferação celular, por meio de mecanismos de estimulação intrácrinos, uma vez que esse receptor está altamente expresso no núcleo dessas células ao longo da gestação (Fig. 5). Estes resultados são condizentes com as observações de Xu et al. (1998), que identificaram a importante correlação entre a expressão do FGFR2 e o estímulo da atividade mitogênica para a proliferação e formação da parte trofoblástica da placenta de ratos, por meio da utilização de um gene inibidor da atividade desse receptor.

Segundo a literatura, a atividade proliferativa celular pode ser influenciada por outros FGFs: FGF4 (Baczyk et al., 2005; Suzuki et al., 2001), FGF7 (Palmieri et al., 2003), FGF8 (Suzuki et al., 2001; Xu et al., 1998), FGF9 (Miyagi et al., 1999) e FGF10 (Xu et al., 1998). Para Baczyk et al. (2005), o FGF4 estimula a permanência da célula em seu estado proliferativo. Suzuki et al. (2001), ao estudarem testículos normais e tumorais, observaram, por meio da marcação da atividade proliferativa a partir do $\mathrm{Ki}-67$, intensa área mitogênica e alta expressão de FGF4, FGF8 e FGFR1. Os resultados do presente estudo assemelham-se aos de Suzuki et al. (2001). Observou-se alta correlação positiva entre 0 FGFR1 e o Ki-67 no epitélio e no estroma maternos, e correlação significativa no estroma fetal $r=0,358(\mathrm{P}=0,0068)$ (Fig. 5).

É possível concluir que, na placenta bubalina, a modulação da proliferação celular parece não estar relacionada somente ao bFGF, mas sim à ação conjunta entre bFGF e outros fatores, como, por exemplo, FGF4, FGF8 ou FGF10. O bFGF parece modular a atividade proliferativa do epitélio fetal por meio da ativação do FGFR2. A ativação do FGFR1 e a conseqüente modificação do fenotipo celular devem ocorrer, provavelmente, a partir da ligação de outro agente indutor de proliferação da família dos FGF.

\section{REFERÊNCIAS BIBLIOGRÁFICAS}

ARESE, M.; CHEN, Y.; FLORKIEWICZ, R.Z. et al. Nuclear activities of basic fibroblast growth factor: potential of low-serum growth mediated by natural or chimeric nuclear localization signals. Mol. Biol. Cell, v.10, p.1429-1444, 1999.

BACZYK, D.; DUNK, C.; HUPPERTZ, B. et al. Bipotential behavior of cytotrophoblasts in first trimester chorionic villi. Placenta, v.27, p.367-374, 2005.

BAMBERGER, A.M.; SUDAHL, S.; BAMBERGER, C.M. et al. Expression patterns of the cell-cycle inhibitor p27 and the cell-cycle promoter Cyclin E in the human placenta throughout gestation: Implications for the control of proliferation. Placenta, v.20, p.401-406, 1999.

BLASIO, A.M.; CARNITINI, C.; VIGANO, P. et al. Basic fibroblast growth factor messenger ribonucleic acid levels in human placentas from normal and pathological pregnancies. Mol. Hum. Rep., v.3, p.1119-1123, 1997.

BOOS; A.; JANSSEN; V.; MÜLLING, C. Proliferation and apoptosis in bovine placentomes during pregnancy and around induced and spontaneous parturition as well as in cows retaining the fetal membranes. Reproduction, v.126, p.469-480, 2003.

CAMPOS, D.B. Imunolocalização do VEGF, bFGF e seus recptores na placenta bovina e influência destes fatores sobre a produção de progesterone pelas células placentárias em cultura. 2005. 193f. Tese (Doutorado em Ciências) - Faculdade de Medicina Veterinária e Zootecnia, Universidade de São Paulo, São Paulo.

CATTINI, P.A.; NICKEL, B.; BOCK, M. et al. Immunolocalization of basic fibroblast growth factor (bFGF) in growing and growth-inhibited placental cells: a possible role for bFGF in placental cells development. Placenta, v.12, p.341-352, 1991.

CORREIA-da-SILVA, G.; BELL, S.C.; PRINGLE, J.H. et al. Patterns of uterine cellular proliferation and apoptosis in the implantation site of the rat during pregnancy. Placenta, v.25, p.538-547, 2004

DAVIS, M.G.; ZHOU, M.; ALI, S. et al. Intracrine and autocrine effects of basic fibroblast growth factor in vascular smooth muscle cells. J. Mol. Cell. Card., v.29, p.1061-1072, 1997. 
FANTL, W.J.; JOHNSON, D.E.; WILLIAMS, L.T Signalling by receptor tyrosine kinases. Annu. Rev. Biochem., v.62, p.453-481, 1993.

FERRIANI, R.A.; AHMED, A.; SHARKEY, A. et al. Colocalization of acid and basic fibroblast growth factor (FGF) in human placenta and the cellular effects of bFGF in trophoblast cell line JEG-3. Growth Factors, v.10, p.259-268, 1994.

FISCHER, S.; DRAPER, B.W.; NEUMANN, C.J. The zebrafish fgf24 mutant identifies an additional level of Fgf signaling involved in vertebrate forelimb initiation. Development, v.130, p.3515-3524, 2003.

GERDES, J.; LEMKE, H.; BAISCH, H. et al. Cell cicle analyses of a cell proliferation-associated human nuclear antigen defined by the monoclonal antibody Ki-67. $J$. Immunol., v.133, p.1710-1715, 1984.

GRUNDKER, C.; KIRCHNER, C. Uterine fibroblast growth factor-2 and embryonic fibroblast growth factor receptor-1 at the beginning of gastrulation in the rabbit. Anat. Embryol., v.194, p.169-175, 1996.

HOFFMANN, B.; SCHULER, G. The bovine placenta; a source and target of steroid hormones: observations during the second half of gestation. Dom. Anim. Endocrinol., v.23, p.309-320, 2002.

JOY, A.; MOFFETT, J.; NEARY, K. et al. Nuclear accumulation of FGF-2 is associated with proliferation of human astrocytes and glioma cells. Oncogene, v.14, p.171-183, 1997.

LAVEN, R.A.; PETERS, A.R. Gross morphometry of the bovine placentome during gestation. Rep. Dom. Anim., v.36, p.289-296, 2001.

MIYAGI, N.; KATO, S.; TERASAKI, M. et al. Fibroblast growth factor-9 (glia-activating factor) stimulates proliferation and production of glial fibrillary acidic protein in human gliomas either in the presence or in the absence of the endogenous growth factor expression. Oncol. Rep., v.6, p.87-92, 1999.

MYERS, J.M.; MARTINS, G.G.; OSTROWSKI, J. et al. Nuclear trafficking of FGFR1: A role for the transmembrane domain. J. Cell. Biochem., v.88, p.12731291, 2003.

ORR-URTREGER, A.; BEDFORD, M.T.; ARMAN, B.E. et al. Dev. Biol., v.158, p.475-486, 1993.

PALMIERI, C.; ROBERTS-CLARK, D.; ASSADISABET, A. et al. Fibroblast growth factor 7, secreted by breast fibroblasts, is an interleukin- $1 \beta$-induced paracrine growth factor for human breast cells. J. Endocrinol., v.177, p.65-81, 2003.

PFARRER, C.; BERISHA, B.; SCHULER, G. et al. Expression and localization of mRNA for fibroblast growth factor (FGF) family members and FGF-receptor (FGFR) mRNAs in bovine placentomes from early gestation until term. Placenta, v.24, p.A.29, 2003.

PFARRER, C.; WEISE, S.; BERISHA, B. et al. fibroblast growth factor (FGF) -1, FGF2, FGF7 and FGF receptors are uniformly expressed in trophoblast giant cells during restricted trophoblast invasion in cows. Placenta, v.27, p.758-770, 2006.

POWERS, C.J.; McLESKEY, S.W.; WELLSTEIN, A. Fibroblast growth factors, their receptor and signaling. Endocr. Relat. Cancer, v.7, p.165-197, 2000.

PRATS, H.; KAGHAD, H.; PRATS, A.C. et al. High molecular mass forms of basic fibroblast growth factor are initiaded by alternative CUG codons. Proc. Nat. Acad. Sci. U.S.A, v.86, 1836-1840, 1989.

QUARTO, N.; TALARICO, D.; FLOKIEWICZ, R. et al. Selective expression of high molecular weight basic fibroblast growth factor confers a unique phebotype to NIH3T3 cells. Cell Regul., v.2, p.699-708, 1991.

REDMER, D.A.; WALLACE, J.M.; REYNOLDS, L.P. Effect of nutrient intake during pregnancy on fetal and placental growth and vascular development. Dom. Anim. Endocrinol., v.27, p.199-217, 2004.

RENKO, M.; QUARTO, N.; MORIMOTO, T. et al. Nuclear and cytoplasmic localization of different basic fibroblast growth factor species. J. Cell. Physiol., v.144, p.108-114, 1990.

SO, F.; DALEY, T.D.; JACKSON, L. et al. Immunohistochemical localization of fibroblast growth factors FGF1 and FGF2, and receptors FGFR2 and FGFR3 in the epithelium of human odontogenic cysts and tumors. J. Oral Pathol. Med., v.30, p.428-433, 2001.

STACHOWIAK, M.K.; FANG, X.; MYERS, J.M. et al. Integrative nuclear FGFR1 signaling (INFS) as a part of a universal "feed-forward-and-gate" signaling module that controls cell growth and differentiation. J. Cell. Biochem., v.90, p.662-691, 2003.

SUZUKI, K.; TOKUE, A.; KAMIAKITO, T. et al. Predominant expression of fibroblast growth factor (FGF) 8, FGF4, and FGF receptor 1 in nonseminomatous and higly proliferative components of testicular germ cell tumors. Virchow Arch, v.439, p.616-621, 2001.

WEI, P.; YU, F.Q.; CHEN, X.L. et al. VEGF, bFGF and their receptors at the fetal-maternal interface of the rhesus monkey. Placenta, v. 25, p. 184-196, 2004.

XU, X.; WEINSTEIN, M.; LI, C. et al. Fibroblast growth factor receptor 2 (FGFR2)- mediated reciprocal regulation loop between FGF8 and FGF10 is essential for limb induction. Development, v.125, p.753-765, 1998.

YU, Z.X.; SADATOSHI, B.; FU, Y.M. et al. Localization of basic fibroblast growth factor in bovine endotelials cells: immunohistochemical and biochemical studies. Exp. Cell Res., v.204, p.247-259, 1993.

ZHENG, J.; VAGNONI, K.E.; BIRD, I.M. et al. Expression of basic fibroblast growth factor, endothelial mitogenic activity, and angiotensin II Type-1 receptors in the ovine placenta during the third trimester of pregnancy. Biol. Rep., v.56, p.1189-1197, 1997. 